\title{
The need to carry out re-inventory of plant pathogenic fungi
}

\author{
Lei Cai ${ }^{1}$, Dhanushka Udayanga ${ }^{1,2}$, Dimuthu S. Manamgoda ${ }^{1,2}$, Sajeewa S.N. Maharachchikumbura ${ }^{1,2}$, \\ Eric H.C. McKenzie ${ }^{3}$, Liang Dong Guo ${ }^{1}$, Xing Zhong Liu ${ }^{1}$, Ali Bahkali ${ }^{4} \&$ Kevin D. Hyde ${ }^{2,4}$
}

${ }^{1}$ Key Laboratory of Systematic Mycology \& Lichenology, Institute of Microbiology, Chinese Academy of Sciences, Beijing 100190, P.R. China; ${ }^{2}$ School of Science, Mae Fah Luang University, Thasud, Chiang Rai 57100, Thailand; ${ }^{3}$ Landcare Research, Private Bag 92170, Auckland, New Zealand; ${ }^{4}$ King Saud University, College of Science, Botany and Microbiology Department, P.O. Box: 2455, Riyadh 1145, Saudi Arabia

Author for correspondence: Lei Cai, e-mail: mrcailei@gmail.com

\section{OUTLINE}

Plant pathogenic fungi have long been documented through concerted efforts of mycologists and plant pathologists; these records have served as the basis for regional and countrywide checklists which have since been put into databases listing hosts and associated fungi. They are used by governments and scientists to formulate trade quarantine policies and determine research funding, such as in plant breeding programs and disease control. With the ability to use molecular characters to study the systematics of fungi it is clear that morphologically defined species are often large complexes comprised of genetically and biologically distinct species. Use of molecular techniques to examine species complexes has revealed cryptic species in many important plant pathogenic genera, e.g. Botryosphaeria, Colletotrichum, Fusarium, and Mycosphaerella. It has occurred to such an extent that existing checklists and databases need updating. It is important that the data from these studies, including changes in taxonomy and nomenclature, be incorporated into the databases of plant pathogenic fungi to support accurate plant quarantine decisions. In addition, epitypifying fungi by re-collecting material from type habitats and isolating the organism into pure culture will provide essential materials for systematics studies to further clarify the taxonomy and phylogeny of plant pathogenic fungi. Overall, we conclude that disease lists are likely to be highly outdated and advocate the need for countrywide re-inventory of plant pathogens. As a result of these studies, tools can be developed that use morphological or molecular characters, or both, to promote accurate identification of plant pathogenic fungi.

Key words: Cochliobolus, Colletotrichum, Diaporthe, Fusarium, Phomopsis, cryptic species, disease associated fungi, quarantine.

\section{Introduction}

There have been worldwide concerted efforts by generations of mycologists and plant pathologists to document plant disease-associated fungi (Roger, 1951-1954; Holliday, 1980; Kohler et al., 1996), although the disease causal agents are probably better known in temperate than tropical regions (Hofmann et al., 2010). Surveys of plant pathogens have resulted in the publication of numerous checklists (Peregrine \& Kassim, 1982; Dingley et al., 1981; McKenzie \& Jackson, 1986; Hyde \& Alcorn, 1993) and more recently many of these have been incorporated into databases such as: USDA, http://nt.ars-grin.gov/ fungaldatabases/fungushost/fungushost.cfm; Database of Plant Disease Names in Japan, www.gene.affrc.go.jp/ databases-micro_pl_diseases_en.php; New Zealand Fungi, http://nzfungi.landcareresearch.co.nz; Fungos relatados em plantas no Brasil - http://pragawall.cenargen.embrapa. br/aiqweb/michtml/micbanco01a.asp. These lists of plant pathogenic fungi have been extremely important in formulating quarantine policies and thus have an immense impact on trade and global biosecurity.

Traditionally, researchers primarily relied on morphology to identify the plant-associated fungi. Usually surveys would be carried out, disease material collected, dried and returned to the laboratory where the associated fungi were later identified (Hyde \& Alcorn, 1993). Molecular data have rapidly advanced the understanding of species boundaries and relationships in several important plant pathogenic genera, revealing numerous cryptic species (Cai et al., 2009; Kvas et al., 2009; Summerell et al., 2010). Databases usually continue to cite fungal taxa recorded in dated publications, but as our knowledge of disease-associated fungi has increased, the checklists and databases have become more and more inaccurate. This has occurred to such an extent that existing checklists (e.g. Anonymous, 1960; Guba, 1961; Raabe, 1966) and databases need updating. It is therefore imperative to recollect many of these pathogens in species complexes and re-identify them based on modern protocols and updated species concepts. For example, Phoulivong et al. (2010a) have demonstrated that the previously believed axiom that "most of the fruit rot diseases in tropics are caused by Colletotrichum gloeosporioides" was wrong. Mycologists therefore need to re-identify all these diseases and give them names that reflect their natural relationships.

In a recent paper Hyde et al. (2010) were of the opinion that plant pathologists and mycologists should re-inventory Australian plant pathogens in order to make quarantine measures more effective. The purpose of this 
paper is to give examples of some selected tropical plant pathogenic genera where the utilization of updated species concept and species recognition criteria (Cai et al., 2011) has improved the discrimination for delimiting species. These examples illustrate the need for fresh inventories of tropical plant pathogens to be carried out in all countries, to ensure that countries have an accurate understanding of the fungal pathogens within their boundaries and, perhaps more importantly, are fully aware of the quarantine pathogens that need to be kept out.

\section{Phylogenetic Methodology}

Sequences for selected fungal genera were downloaded from GenBank and aligned using Clustal X. The alignment was optimized manually to allow maximum alignment and maximum sequence similarity. Gaps were treated as missing data. Phylogenetic analysis was carried out based on the aligned dataset using PAUP* 4.0b10 (Swofford, 2002). Ambiguously aligned regions were excluded from all analyses. Trees were inferred using the heuristic search option with TBR branch swapping and 1000 random sequence additions. Maxtrees were unlimited, branches of zero length were collapsed, and all multiple parsimonious trees were saved. Trees were figured in TreeView (Page, 1996).

\section{Selected Examples}

\section{Cochliobolus and its anamorphs}

Cochliobolus, which was introduced by Drechsler (1934), is typified by C. heterostrophus (Drechsler) Drechsler. Previously, many species of Cochliobolus had been included in Ophiobolus, a genus with bitunicate asci and scolecospores (Drechsler, 1934; Arx \& Olivier, 1952). Alcorn (1983) thought that the characters used to distinguish Pseudocochliobolus from Cochliobolus were artificial and treated the former as a synonym. However, the above treatments were all based on morphology, and the genus has not been well examined using modern protocols. The classical identification of Cochliobolus and its anamorphs has encountered some problems due to the plasticity of morphological traits under different growth conditions (Old \& Roberston, 1969; Hosokawa et al., 2003). We predict that new molecular developments will lead to a rearrangement of taxa at the specific or subspecific level in the near future.

Currently, 56 Cochliobolus species names are listed in Index Fungorum and 20 are listed in the USDA database, and the Dictionary of the Fungi (Kirk et al., 2008) estimates that the genus comprises 22 species. Cochliobolus has anamorphs in Bipolaris and Curvularia and there are 73 estimated species of Bipolaris and 54 estimated species of Curvularia (Kirk et al., 2008); teleomorph / anamorph connections have rarely been resolved for Cochliobolus. An extensive re-inventory of Cochliobolus and its anamorphs should be carried out because 1) some species defined based on morphology often contain more than one phylogenetic species, which are increasingly being formally introduced; 2) numerous species that do not have ex-type cultures to facilitate DNA extraction and epitypifications of many taxa are urgently needed; and 3) there are still arguments regarding the synonymy of Pseudocochliobolus with Cochliobolus (Berbee et al., 1999) and placement of Bipolaris and Curvularia anamorphs which are shown to be phylogenetically distant (Groves \& Skolko, 1945; Puttterill, 1954; Ellis, 1966; 1971; Alcorn, 1983), and these are unlikely to be resolved until a larger number of samples from living ex-type cultures are included in analyses.

GenBank likely contains many wrongly named taxa within Cochliobolus (Figure 1). Twenty-four ITS sequences named as Cochliobolus lunatus were downloaded from GenBank and aligned with ITS sequence data derived from ex-type cultures of Cochliobolus species. "Cochliobolus lunatus" sequences are scattered throughout the phylogram containing these ex-types, indicating that numerous strains labeled $C$. lunatus in GenBank have been misidentified. The confusion among Cochliobolus and its anamorphs indicate that many records in countrywide checklists are likely to be wrong and a re-assessment using modern protocol is necessary.

\section{Colletotrichum}

The previous understanding of Colletotrichum species was based on morphology and to a lesser extent on cultural characters (Than et al., 2008; Hyde et al., 2009). Sutton (1980) accepted 40 species in Colletotrichum based on morphology in culture, and until very recently this taxonomic scheme was followed by most researchers. Hyde et al. (2009) published a list of 66 current names with notes, while Cai et al. (2009) detailed ways in which to deal with species concepts in the genus using a polyphasic approach. Prior to these publications several grass-associated Colletotrichum species had been epitypified and several new species formally regarded as C. graminicola sensu lato had been introduced (Crouch et al., 2009; Crouch \& Beirn, 2009). Similarly, Damm et al. (2009) described 18 species with curved spores, of which ten were epitypes and four were new species. These publications set a standard for revising the various Colletotrichum species complexes and have resulted in several publications revealing and describing species within the C. gloeosporioides species complex (Rojas et al. 2010; Phoulivong et al., 2010b). These revisions were only possible following the epitypification of C. gloeosporioides (Cannon et al., 2008). Colletotrichum acutatum and $C$. boninense are likely to be treated in a similar way in a future issue of Studies in Mycology (Damm et al. pers. comm.). Hyde et al. (2009) listed all currently accepted species of Colletotrichum, with the information of type specimens, ex-type cultures, multilocus sequences and references to each species. Such summarizing of information will significantly increase the efficiency and accuracy for anyone who wants to identify a Colletotrichum 
The need to carry out re-inventory of plant pathogenic fungi

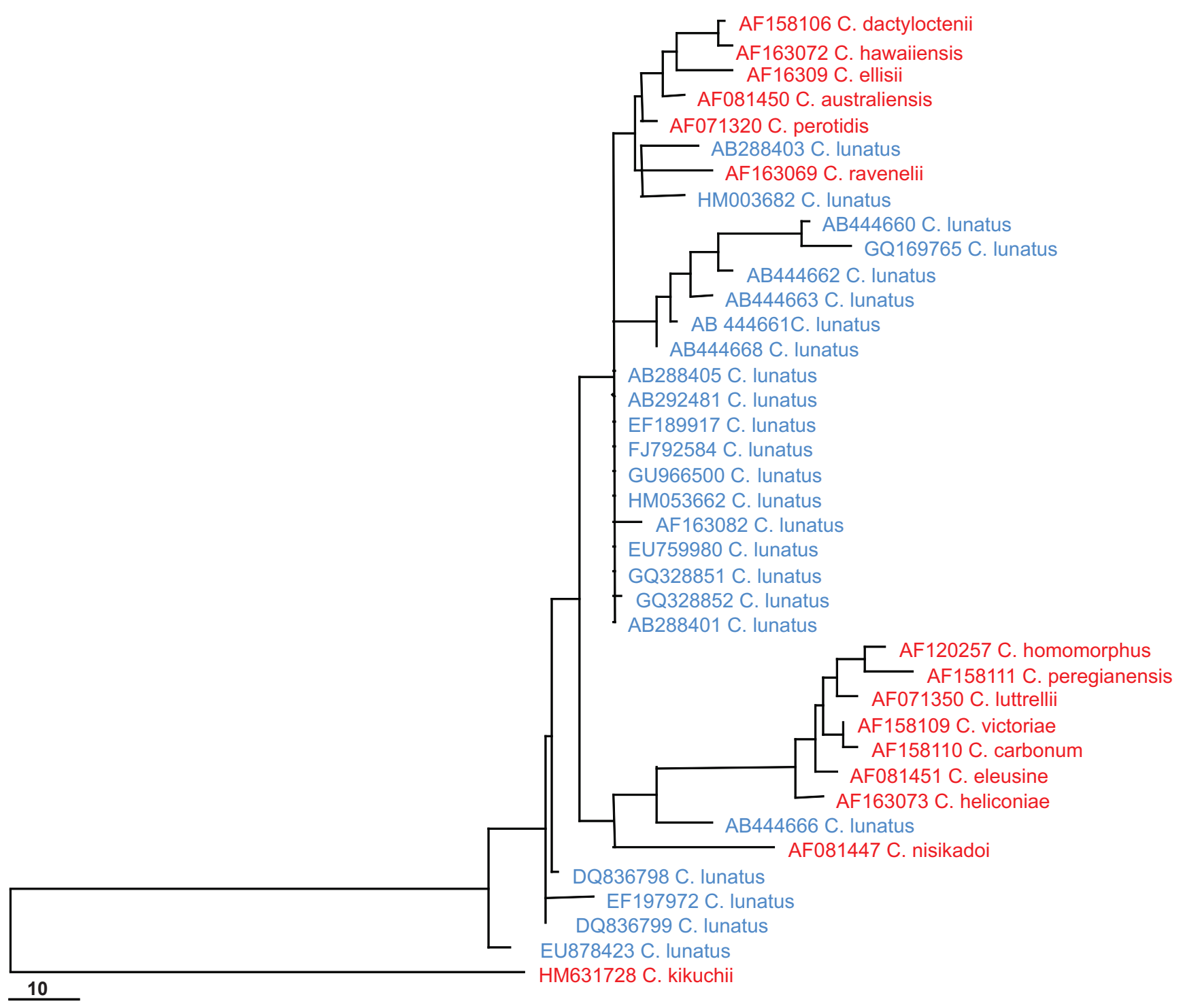

FIGURE 1 - Maximum parsimony phylogram generated from ITS sequence analysis of sequences named "Cochliobolus lunatus" (shown in blue) downloaded from GenBank with those derived from Cochliobolus ex-type cultures (shown in red). Data were analyzed with random sequence addition, unweighted parsimony, and treating gaps as missing data. The tree is rooted with Cochliobolus kikuchii.

pathogen. Other important pathogenic groups should also be summarized with such data.

Prihastuti et al. (2010) neotypified C. falcatum with a fresh collection from the original sugarcane field in Java, Indonesia from which the type was described. This species causes red stripe of sugarcane leaves and can be serious in some countries (e.g. India, Pakistan, Bangladesh and Taiwan, Crouch \& Beirn, 2009). In a phylogenetic analysis, we downloaded all ITS sequences named $C$. falcatum from GenBank (accessed 1 July 2010) and aligned them with sequences from other closely related taxa, including some of the sequences from types. The C. falcatum GenBank accessions are indicated by their GenBank accession numbers in green while the reference taxa are shown in blue (Figure 2). Comparison of ITS sequence data from the neotype against sequences deposited in GenBank shows that only one ITS sequence (AB462376, generated from strain MAFF306170) is identical to the neotype (100\% similarity), and only four of the 23 C. falcatum sequences cluster in the same clade in the parsimonious tree (shown in red) (Figure 2). The "C. falcatum" strains scattered throughout the tree indicate that some sequences deposited in GenBank have $C$. falcatum names that are almost certainly wrongly applied. The diversity of ITS sequences of $C$. graminicola and $C$. gloeosporioides deposited in GenBank is even more diverse (Crouch et al., 2009; Cai et al., 2009).

As similar changes are expected to take place in other species complexes in Colletotrichum, it is certain that records of Colletotrichum plant disease-associated fungi in all tropical countries is outdated. For example, 
L. Cai et al.

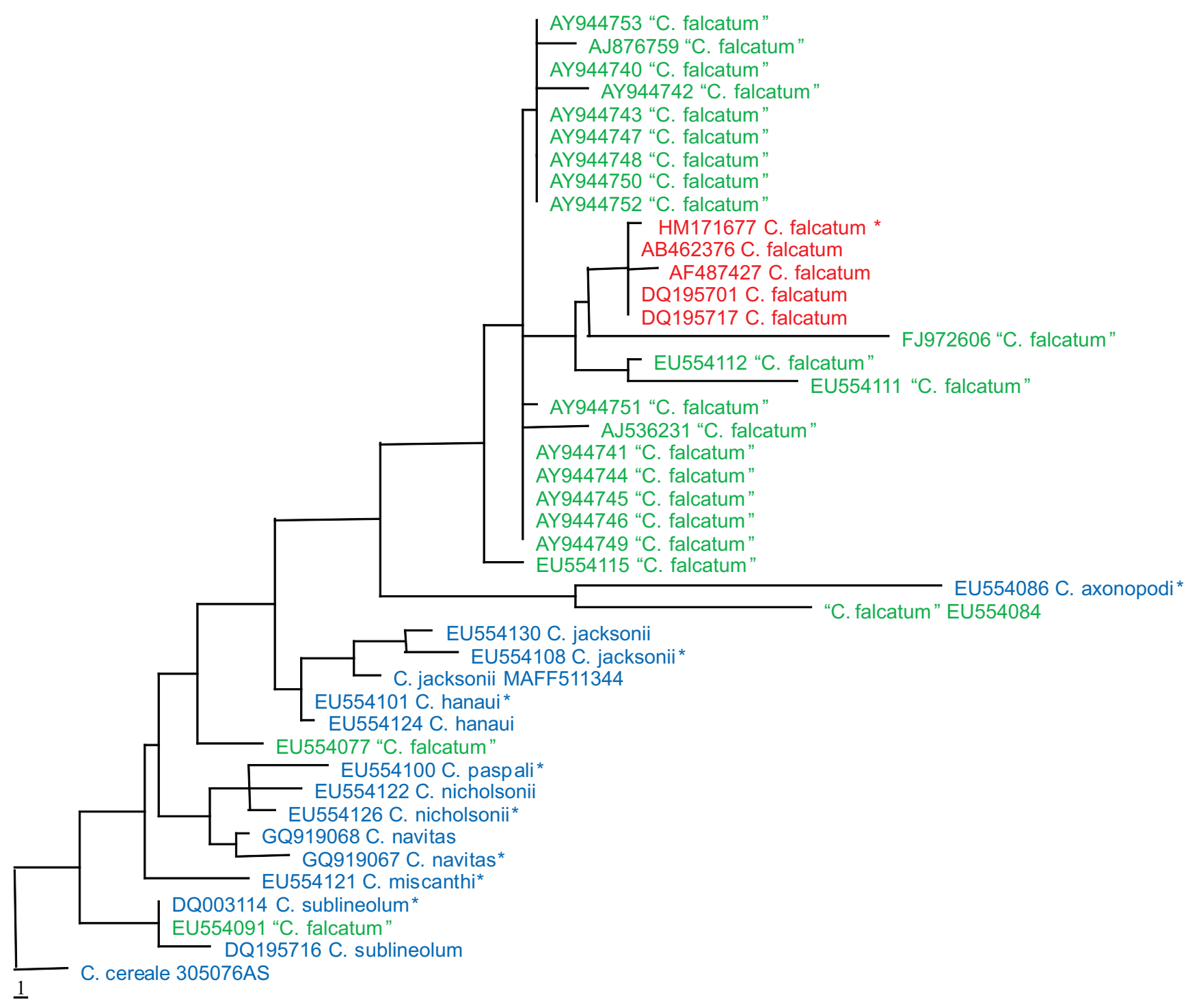

FIGURE 2 - Maximum parsimony phylogram generated from sequence analysis of ITS sequences of "Colletotrichum falcatum" downloaded from GenBank and other related taxa. Data were analyzed with random sequence addition, unweighted parsimony and treating gaps as missing data. ITS sequences of "C. falcatum" are shown in green; neotypes and other identified C. falcatum strains are shown in red. Other reference taxa are shown in blue. * indicates the sequences derived from ex-type cultures. The tree is rooted with Colletotrichum cereale.

Dingley et al. (1981), following the accepted protocols and taxonomy of the time, recorded Glomerella cingulata on 66 different host plants in 32 families. In addition, Dingley et al. (1981) listed a further 25 host records, based on earlier publications, as either Glomerella sp. or Colletotrichum $\mathrm{sp}$; numerous other diseases on a broad range of hosts were recorded as Glomerella tucumanensis, Colletotrichum acutatum, C. capsici, C. circinans, C. crassipes, C. dematium, C. fructigenum, C. graminicola, C. musae, C. orbiculare and C. truncatum. Judging by the fairly wide host ranges ascribed to some of these species, and to recent knowledge on Colletotrichum taxonomy, it is extremely doubtful that many of these records can be accepted. They certainly do not provide the necessary certainty required for robust biosecurity decisions, and there is obviously an urgent need for a re-inventory of these pathogens. Although the above described situation applies to Pacific island records of these fungi, the same uncertain situation exists all over the world.

\section{Fusarium}

Fusarium contains economically important plant pathogens, several species that are important producers of mycotoxins, the latter being recognized as human pathogens and often isolated as endophytes (Summerell et al., 2010). For this reason the genus has been relatively well studied 
and species concepts are fairly advanced. In 2001 there were an estimated 50 Fusarium species, while estimates in Kirk et al. (2008) were 111, indicating a rapid increase in the naming of species. Three basic concepts are currently used to define species of Fusarium - morphological, biological and phylogenetic (Leslie \& Summerell 2006; Summerell et al., 2010); however, a single morphological species often contains several biological or phylogenetic species. The EF-1 $\alpha$ gene is regarded as a particularly good marker for species of Fusarium (O'Donnell et al., 2009; Summerell et al., 2010). However, genes such as rpb-2, $\beta$-tubulin, calmodulin and IGS rDNA, polygalacturonases, mitochondrial small subunit ribosomal RNA, phosphate permease, nitrate reductase, MAT 1 and MAT2 have also been used (O'Donnell et al., 2009). One example of progress in Fusarium is the understanding of the Gibberella fujikuroi complex. This complex comprises an assemblage of Fusarium species with similar and overlapping morphological traits (Leslie et al., 2001; Kvas et al., 2009). Devastating diseases of many economically important plants have been linked to species in this complex, which also produce a wide range of secondary metabolites or mycotoxins that contaminate food and feedstuffs worldwide, causing a variety of diseases in humans and animals (Kvas et al., 2009). Currently 34 morphospecies are recognized in the complex based on morphological species recognition, ten are well-characterised biological species or so-called mating populations, and phylogenetic species recognition show at least 50 distinct phylogenetic species or lineages (Kvas et al., 2009). However, the resolving power of phylogenetic species recognition far outweighs that of morphological or biological species recognition (Kvas et al., 2009).

Recognition of all known Fusarium species in the Gibberella fujikuroi complex is possible by applying only phylogenetic species recognition. However, such identifications may yield results that are not biologically meaningful (Summerell et al., 2010). Phylogenetic species recognition is therefore generally used in combination with morphological and biological species recognition in this complex. Most of the current species definitions and descriptions in this complex are based on a polyphasic or integrative taxonomic approach (Aoki et al. 2005; Kvas et al., 2009). For example, through morphological and cultural characterization, multilocusphylogeneticanalysesandsexual compatibility studies, Amata et al. (2010) demonstrated that F. brevicatenulatum and F. pseudoanthophilum belonged to the same species. This integrative approach also extends to routine species identifications.

Because of the rapid changes and advances in understanding the species complexes in Fusarium and the increase in numbers of cryptic species introduced (Kvas et al., 2009; Summerell et al., 2010) there is a need for re-inventory of this important group of fungi. The identification in this re-inventory should be based on multilocus phylogenetic tools and updated species concepts (Cai et al., 2011). Molecular protocol that could readily diagnose species accurately and quickly has been done for some complexes (e.g. Zhang et al., 2008).

\section{Phomopsis}

Phomopsis is an important phytopathogenic genus, introduced by Saccardo (1905). Phomopsis are anamorphic Diaporthe and occur as endophytes, pathogens or saprobes on a wide range of hosts (Mostert et al., 2001). There are over 800 species based on host associations (Uecker, 1988), but recent phylogenetic studies suggest that host association is of minor importance in the taxonomy of this genus (Rehner \& Uecker, 1994; Murali et al., 2006).

Stem canker of Helianthus annus (sunflower) was first recorded in 1980 in the former Yugoslavia, and the causative agent of this serious disease was described as Diaporthe helianthi, with a Phomopsis helianthi anamorph (Cvetkovic et al., 1981). This name often appears in the literature, and the fungus has been widely studied for its genetic variability, epidemiology and phytosanitatory concerns as it causes a devastating disease on economically important hosts all over the world. We downloaded 44 ITS sequences named Diaporthe helianthi, and some of the type derived sequences of Phomopsis/Diaporthe from GenBank (accessed 31 August 2010). The phylogram generated from the analysis shows the close relationship of most of the sequences to the ex-type culture, but there are eight records that deviate significantly from the type (Figure 3 ). These are either due to misidentification, plasticity in the nature of morphological characters, or to obscure delimitation of morphological species boundaries.

Diaporthe helianthi shows a narrow range of host distribution compared to most other members of Phomopsis/Diaporthe. Although genetic variability among the various isolates of $D$. helianthi has been widely studied in Australia and Europe (Pecchia et al., 2004; Recab et al., 2004), it is unsure if all isolates in these studies have correctly applied names. The ambiguity and significant deviation of several GenBank records emphasizes the importance of the use of ex-type cultures in the identification of this important pathogen. In other words, the existence of an ex-type culture would avoid misidentification of the pathogen isolated from distant geographical locations.

The analysis of ITS sequence data for taxa within Phomopsis/Diaporthe may identify well supported groups of closely related taxa, but phylogenetic relationships for more distantly related taxa from a wide range of hosts cannot be determined with a high level of confidence. Analysis of multiple genes will be required to sort out phylogenetic relationships among species of Phomopsis/ Diaporthe (Farr et al., 2002), on which to base taxonomic revision. As a result of those systematics studies, tools to accurately identify species of Phomopsis can then be developed and utilized by diagnosticians, plant pathologists, and by plant regulatory agencies. 
L. Cai et al.

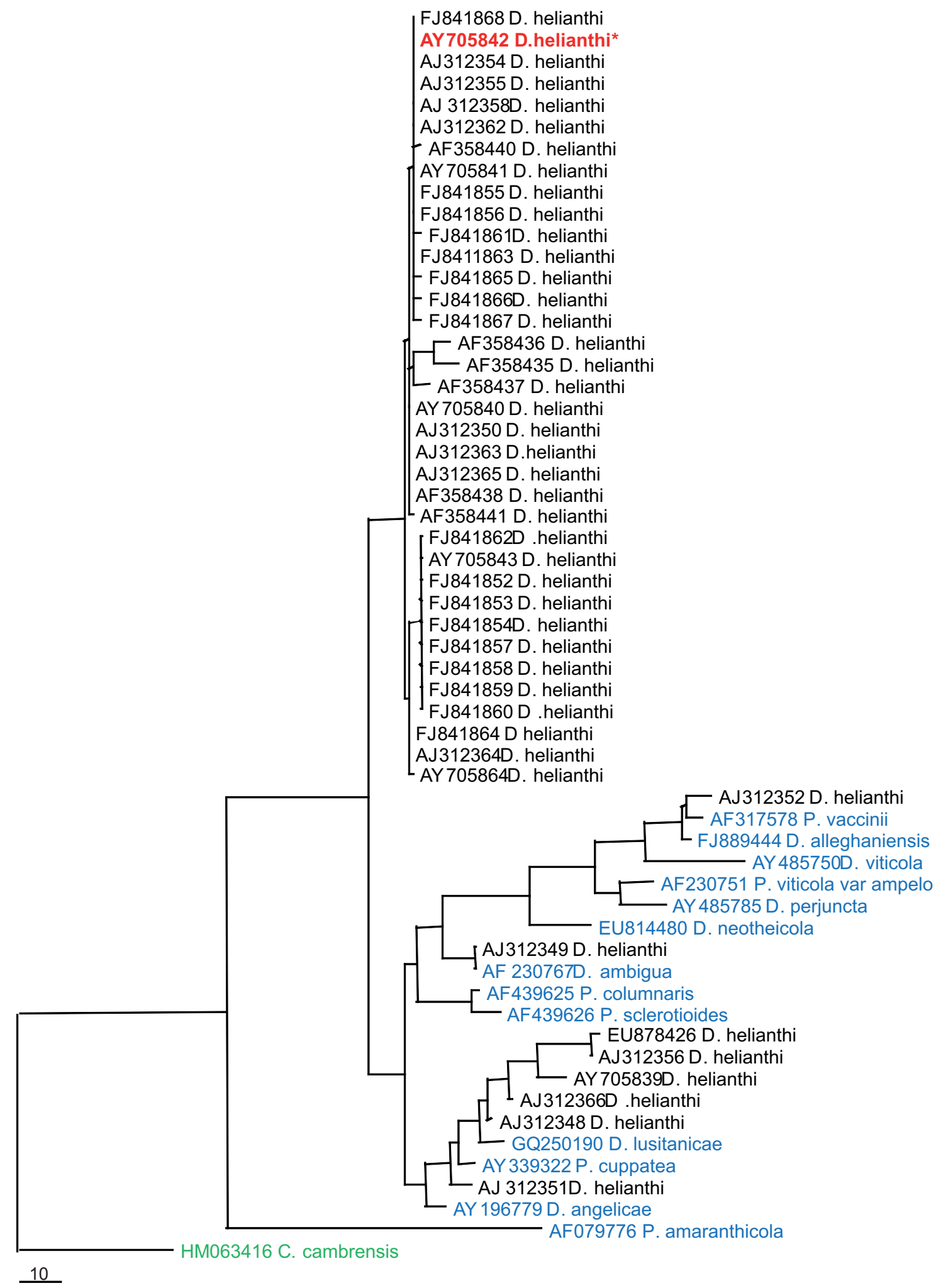

FIGURE 3 - Maximum parsimony phylogram generated for the ITS sequence analysis from sequences of "Diaporthe helianthi" available in GenBank with available sequences derived from ex-type cultures. ITS sequences of $D$. helianthi downloaded from GenBank are shown in black. The type derived sequence of $D$. helianthi is shown in red and other type derived records are in blue. Data were analyzed with random addition sequence, unweighted parsimony and treating gaps as missing data. The tree is rooted with Corynespora cambrensis. 


\section{Concluding Remarks}

We have discussed several important genera of plant pathogens and shown how molecular studies have revealed the existence of species complexes and made it possible to characterize and describe many new cryptic species. Similar changes are also occurring in several other important pathogenic genera such as Botryosphaeria (Denman et al., 2000; Crous et al., 2006; Phillips et al., 2008), Mycosphaerella (Crous et al., 2009; Bensch et al., 2010) and Phoma (Aveskamp et al., 2008; 2010).

The systematics and naming of plant pathogenic fungi is extremely important (Rossman \& Palm-Hernández, 2008). Species concepts for many important plant pathogenic fungi have changed due to the use of molecular tools to study those organisms. Morphology has always played a key role in delimiting species and genera. Additionally, some species were described based on the host on which they occurred, because most plant pathogenic fungi were thought to be highly host specific. More recently molecular studies have shown that morphological species in plant pathogenic fungi are often species complexes that comprise genetically and biologically distant species. Previously, in studying plant pathogenic fungi, obtaining a living culture was not a significant concern for most mycologists as herbaria were used for typification (Hawksworth, 1974). In modern practice, mycologists are now using molecular characters and sequence analyses to study evolutionary relationships and classify plant pathogenic fungi. This practice relies on living cultures as high quality DNA samples are less likely to be extracted from dried herbarium samples. Because living cultures were not a strict necessity for the hostoriented and morphological species concepts, most of the currently applied names of plant pathogenic fungi do not have a living ex-type culture. This has prevented studies of the organism's biology as well as extraction of DNA for molecular analyses.

Given the importance of living cultures for understanding the biology and systematics of plant pathogenic fungi (Abd-Elsalam et al., 2010), there is an urgent need to epitypify many fungal species and reidentify pathogens, especially those previously placed in the species complex. This may necessitate returning to the original collecting localities and original hosts to collect morphologically identical specimens and to deposit them as epitypes, supplemented with ex-epitype strains (Hyde \& Zhang, 2008). Revised checklists and databases should be supported by herbarium materials, living cultures and DNA libraries to establish the link between DNA sequences and type specimens for taxonomic verification. The newly established cryptic species should, however, be further studied by plant pathologists for various characters such as host range and severity, and thus to determine if any of them bear quarantine significance. Molecular biologists will also need to develop fast and accurate protocols that can easily distinguish the quarantine-significant ones from their close relatives.

\section{Acknowledgements}

Work on the Dothideomycetes was supported by the TRF/BIOTEC Special Program for Biodiversity Research and Training grant BRT R253012 and work on Colletotrichum was supported by Mae Fah Luang University research grants 51101010029 and 52101010002. Lei Cai acknowledges funding support from CAS (KSCX2-YW-Z1026) and NSFC (31110103906).

\section{References}

Amata R, Burgess L, Summerell B, Bullock S, Liew E, Smith-White J (2010) An emended description of Fusarium brevicatenulatum and $F$. pseudoanthophilum based on isolates recovered from millet in Kenya. Fungal Diversity 43:11-25.

Abd-Elsalam KA, Yassin MA, Moslem MA, Bahkali AH, McKenzie EHC, Stephenson SL, Cai L, Hyde KD (2010) Culture collections, the new herbaria for fungal pathogens. Fungal Diversity 45:21-32.

Alcorn JL (1983) On the genera Cochliobolus and Pseudococchliobolus. Mycotaxon 16:353-379.

Anonymous (1960) Index of Plant Diseases in the United States. USDA. Agricultural Handbook 165:1-531.

Aoki T, O’Donnell K, Scandiani M. (2005) Sudden death syndrome of soybean in South America is caused by four species of Fusarium: Fusarium brasiliense sp. nov., F. cuneirostrum sp. nov., F. tucumaniae, and F. virguliforme. Mycoscience 46:162183.

Arx JA von, Olivier DL (1952) The taxonomy of Ophiobolus graminis Sacc. Transactions of the British Mycological Society 35:29-33.

Aveskamp MM, De Gruyter J, Crous PW (2008) Biology and recent developments in the systematics of Phoma, a complex genus of major quarantine significance. Fungal Diversity 31:118.

Aveskamp MM, de Gruyter J, Woudenberg JHC, Verkley GJM, Crous PW (2010) Highlights of the Didymellaceae: A polyphasic approach to characterise Phoma and related pleosporalean genera. Studies in Mycology 65:1-60.

Bensch K, Groenewald JZ, Dijksterhuis J, Starink-Willemse M, Andersen B, Summerell BA, Shin H-D, Dugan FM, Schroers H-J, Braun U, Crous PW (2010) Species and ecological diversity within the Cladosporium cladosporioides complex (Davidiellaceae, Capnodiales). Studies in Mycology 67:1-94.

Berbee ML, Pirseyedi M, Hubbard S (1999) Cochliobolus phylogenetics and the origin of known, highly virulent pathogens, inferred from ITS and glyceraldehyde-3-phosphate dehydrogenase gene sequences. Mycologia 91:964-977.

Cai L, Hyde KD, Taylor PWJ, Weir B, Waller J, Abang MM, Zhang JZ, Yang YL, Phoulivong S, Liu ZY, Prihastuti H, Shivas RG, McKenzie EHC, Johnston PR (2009) A polyphasic approach for studying Colletotrichum. Fungal Diversity 39:183-204.

Cai L, Giraud T, Zhang N, Begerwo D, Cai GH, Shivas RG (2011) The evolution of species concept and species recognition criteria 
in plant pathogenic fungi. Fungal Diversity DOI 10.1007/s13225011-0127-8

Cannon PF, Buddie AG, Bridge PD (2008) The typification of Colletotrichum gloeosporioides. Mycotaxon 104:189-204.

Cristescu C (2003) A new specis of Phomopsis Sacc. (mitosporic fungi), from Romania. Romanian Journal of Biology-Plant Biology 48:45-49.

Crouch JA, Clarke BB, White JF, Hillman BI (2009) Systematic analysis of falcate-spored graminicolous Colletotrichum and a description of six new species from warm-season grasses. Mycologia 101:717-732.

Crouch JA, Beirn LA (2009) Anthracnose of cereals and grasses. Fungal Diversity 39:19-44.

Crous PW, Slippers B, Wingfield MJ, Rheeder J, Marasas WFO, Philips AJL, Alves A, Burgess TI, Barber PA, Groenewald JZ. (2006) Phylogenetic lineages in the Botryosphaeriaceae. Studies in Mycology 55:235-253.

Crous PW (2009) Taxonomy and phylogeny of the genus Mycosphaerella and its anamorphs. Fungal Diversity 38:1-24.

Cvetcovic MM, Petrov M, Mihaljcevic M (1981) On identity of the causative agent of a serious Phomopsis-Diaporthe diseases in sunflower plant. Nova Hedwigia 35:417-434.

Damm U, Woudenberg JHC, Cannon PF, Crous PW (2009) Colletotrichum species with curved conidia from herbaceous hosts. Fungal Diversity 39:45-87.

Denman PW, Taylor JE, Kang JC, Pascoe I, Michael J (2000) An overview of the taxonomic history of Botryosphaeria, and a reevaluation of its anamorphs based on morphology and ITS rDNA phylogeny. Studies in Mycology 45:29-140.

Dingley JM, Fullerton RA, McKenzie EHC (1981) Records of fungi, bacteria, algae, and angiosperms pathogenic on plants in Cook Islands, Fiji, Kiribati, Niue, Tonga, Tuvalu, and Western Samoa. UNDP/FAO/SPEC Survey of Agricultural Pests and Diseases 2. Rome. SPEC, UNDP, FAO.

Drechsler C (1934) Phytopathological and taxonomic aspects of Ophiobolus, Pyrenophora, Helminthosporium and a new genus Cochliobolus. Phytopathology 24:953-983.

Ellis MB (1966) Dematiaceous hypomycetes. VII: Curvularia, Brachysporium etc. Mycological Papers 106:1-57.

Ellis MB (1971) Dematiaceous Hyphomycetes. Commonwealth Mycological Institute, England.

Farr DF, Castleburry LA, Rossman AY, Putnam ML (2002) A new species of Phomopsis causing twig dieback of Vaccinium vitisidaea (lingonberry). Mycological Research 106:745-775.

Groves JW, Skolko AJ (1945) Notes on seed borne fungi. III. Curvularia. Canadian Journal of Research (C) 23:94-104.

Guba EF (1961) Monograph of Pestalotia and Monochaetia. Cambridge, MA. Harvard University Press.

Hawksworth DL (1974) Mycologist's handbook. Commonwealth Mycological Institute, Kew, Surrey, UK.

Hofmann TA, Kirschner R, Piepenbring M (2010) Phylogenetic relationships and new records of Asterinaceae (Dothideomycetes) from Panama. Fungal Diversity 43:39-53.

Holliday P (1980) Fungus diseases of tropical crops. Cambridge. Cambridge University Press.
Hosokawa M, Tanaka C, Tsuda M (2003) Conidium morphology of Curvularia geniculata and allied species. Mycoscience 44:227237.

Hyde KD, Alcorn JL (1993) Some disease-associated microorganisms on plants of Cape York Peninsula and Torres Strait Islands. Australian Plant Pathology 22:73-83.

Hyde KD, Zhang Y (2008) Epitypification: should we epitypify? Journal of Zhejiang University Science B 10:842-846.

Hyde KD, Cai L, Cannon PF, Crouch JA, Crous PW, Damm U, Goodwin PH, Chen H, Johnston PR, Jones EBG, Liu ZY, McKenzie EHC, Moriwaki J, Noireung P, Pennycook SR, Pfenning LH, Prihastuti H, Sato T, Shivas RG, Taylor PWJ, Tan YP, Weir BS, Yang YL, Zhang JZ (2009) Colletotrichum - names in current use. Fungal Diversity 39:147-182.

Hyde KD, Chomnunti P, Crous PW, Groenewald JZ, Damm U, Ko Ko TW, Shivas RG, Summerell BA, Tan, YP (2010) A case for reinventory of Australia's plant pathogens. Persoonia 25:50-60.

Kirk PM, Cannon PF, Minter DM, Stapers A (2008) The dictionary of the fungi $10^{\text {th }}$ edition. Wallingford UK. CABI.

Kohler F, Pellegrin F, Jackson G, McKenzie EHC (1996) Diseases of cultivated crops in Pacific island countries. South Pacific Commission, Noumea.

Kvas M, Marasas WFO, Wingfield BD, Wingfield MJ, Steenkamp ET (2009) Diversity and evolution of Fusarium species in the Gibberella fujikuroi complex. Fungal Diversity 34:1-21.

Leslie JF, Summerell BA (2006) The Fusarium laboratory manual. Malden MA. Blackwell Publishers.

Leslie JF, Zeller KA, Summerell BA (2001) Icebergs and species in populations of Fusarium. Physiological Molecular Plant Pathology 59:107-117.

McKenzie EHC, Jackson GVH (1986) The fungi, bacteria and pathogenic algae of Solomon Islands. Strengthening plant protection and root crops development in the South Pacific. RAS/83/001, Field Document 11. Suva, Fiji.

Mostert L, Crous PW, Kang JC, Phillips AJL ( 2001) Species of Phomopsis and a Libertella sp. occurring on grapevines with specific reference to South Africa: morphological, cultural, molecular and pathological characterization. Mycologia 93:146167.

Murali TS, Suryanarayanan, TS, Geeta R (2006) Endophytic Phomopsis species: host range and implications for diversity estimates. Canadian Journal of Microbiology 52:673-680.

O'Donnell K, Gueidan C, Sink S, Johnston PR, Crous PW, Glenn A, Riley R, Zitomer NC, Colyer P, Waalwijk C, Lee Tvd, Moretti A, Kang S, Kim HS, Geiser DM, Juba JH, Baayen RP, Cromey MG, Bithell S, Sutton DA, Skovgaard K, Ploetz R, Corby KH, Elliott M, Davis M, Sarver BAJ (2009) A two-locus DNA sequence database for typing plant and human pathogens within the Fusarium oxysporum species complex. Fungal Genetics and Biology 46:936-948.

Old KM, Roberston WM, (1969) Examination of conidia of Cochliobolus sativus recovered from neutral soil using transmission and scanning electron microscopy. Transactions of the British Mycological Society 53:217-221.

Page RDM (1996) TREEVIEW: An application to display phylogenetic trees on personal computers. Computer Applications 
The need to carry out re-inventory of plant pathogenic fungi

in the Biosciences 12:357-358.

Pal AK, Purkayastha RP (1992) New parasitic fungi from Indian mangrove. Journal of Mycopathological Research 30:173-176.

Pecchia S, Mercatelli E, Vannacci G (2004) Intraspecific diversity within Diaporthe helianthi: evidence from rDNA intergenic spacer (IGS) Sequence analysis. Mycopathologia 157:317-326.

Peregrine WTH, Kassim BA (1982) Brunei: A first annotated list of plant diseases and associated organisms. Phytopathological Papers 27:1-87.

Phillips AJL, Alves A, Pennycook SR, Johnston PR, Ramaley A, Akulov A, Crous PW (2008) Resolving the phylogenetic and taxonomic status of dark-spored teleomorph genera in the Botryosphaeriaceae. Persoonia 21:29-55.

Phoulivong S, Cai L, Chen H, McKenzie EHC, Abdelsalam K, Chukeatirote E, Hyde KD (2010a) Colletotrichum gloeosporioides is not a common pathogen on tropical fruits. Fungal Diversity 44:33-43.

Phoulivong S, Cai L, Parinn N, Chen H, Abdelsalam K, Chukeatirote E, Hyde KD (2010b) A new species of Colletotrichum from Cordyline fruticosa and Eugenia javanica causing anthracnose disease. Mycotaxon 114:247-257.

Prihastuti H, Cai L, Phoulivong S, Abdelsalam K, Crouch JA, McKenzie EHC, Hyde KD (2010) Neotypification of Colletotrichum falcatum, the causative agent of red-rot disease in sugarcane. Sydowia 62:683-693.

Puttterill KM (1954) Some graminicolous species of Helminthosporium and Curvularia occurring in south Africa. Bothalia 6:347-378.

Raabe RD (1966) Check list of plant diseases previously unreported in Hawaii. Plant Disease Reporter 50:411-414.

Recab D, Sorbo GD, Reggio C, Zonia A, Firrao G (2004) Polymorphisms in nuclear rDNA and mtDNA reveal the polyphyletic nature of isolates of Phomopsis pathogenic to sunflower and a tight monophyletic clade of defined geographic origin. Mycological Research 108:393-402.

Rehner SA, Uecker FA (1994) Nuclear ribosomal internal transcribed spacer phylogeny and host diversity in the coelomycete
Phomopsis. Canadian Journal of Botany 72:1666-1678.

Roger L (1951-1954) Phytopathologie des pays chauds. Vols 1-3. Paris, Paul Lechevalier.

Rojas EI, Rehner SA, Samuels GJ, Bael SAV, Herre EA, Cannon P, Chen R, Pan J, Wang R, Zhang Y, Peng YQ, Sha T (2010) Colletotrichum gloeosporioides s. 1. associated with Theobroma cacao and other plants in Panama: multilocus phylogenies distinguish host-associated pathogens from asymptomatic endophytes. Mycologia 102:1318-1338.

Rossman AY, Palm-Hernández ME (2008) Systematics of Plant Pathogenic Fungi: Why it matters. Plant Disease 92:1376-1386.

Saccardo PA (1905) Notae mycologicae. Series V. Annales Mycologici 3:165-171.

Santos JM, Phillips AJL (2009) Resolving the complex of Diaporthe / Phomopsis species occuring on Foeniculum vulgare in Portugal. Fungal Diversity 34:111-125.

Summerell BA, Laurence MH, Liew ECY, Leslie JF (2010) Biogeography and phylogeography of Fusarium: a review. Fungal Diversity 43:3-13.

Sutton BC (1980) The Coelomycetes: Fungi Imperfecti with Pycnidia, Acervular and Stromata. Kew, London. Commonwealth Mycological Institute.

Swofford DL (2000) PAUP* 4.0: phylogenetic analysis using parsimony (* and other methods). Sunderland MA. Sinauer Associates.

Than PP, Jeewon R, Hyde KD, Pongsupasamit S, Mongkolporn O, Taylor PWJ (2008) Characterization and pathogenicity of Colletotrichum species associated with anthracnose disease on chilli (Capsicum spp.) in Thailand. Plant Pathology 57:562-572.

Uecker FA (1988) A World list of Phomopsis names with notes on nomenclature, morphology and biology. Contributions from the U.S. National Fungus Collection. Mycologia Memoir 13:9-12.

Zhang N, Geiser DM, Smart CD (2007) Macroarray detection of solanaceous plant pathogens in Fusarium solani species complex. Plant Disease 91:1612-1620. 